\title{
Characterization and Catalytic-Site-Analysis of an Aldo-Keto Reductase with Excellent Solvent Tolerance
}

\author{
Rui Pei, Weiliang Wu, Yuqian Zhang, Libing Tian, Wei Jiang * and Shu-Feng Zhou *(D) \\ College of Chemical Engineering, Huaqiao University, 668 Jimei Blvd., Xiamen 361021, China; \\ ruipeia@163.com (R.P.); wuweiliang@163.com (W.W.); msnzyq@163.com (Y.Z.); libingtian2020@163.com (L.T.) \\ * Correspondence: wjiang@hqu.edu.cn or tianya416@126.com (W.J.); szhou@hqu.edu.cn (S.-F.Z.); \\ Tel.: +86-059-2616-2305 (W.J. \& S.-F.Z.)
}

Received: 23 June 2020; Accepted: 20 July 2020; Published: 1 October 2020

check for updates

\begin{abstract}
Aldo-keto reductases (AKRs) mediated stereoselective reduction of prochiral carbonyl compounds is an efficient way of preparing single enantiomers of chiral alcohols due to their high chemo-, enantio-, and regio-selectivity. To date, the application of AKRs in the asymmetric synthesis of chiral alcohols has been limited, due to the challenges of cloning and purifying. In this work, the aldo-keto reductase (AKR3-2-9) from Bacillus sp. was obtained, purified and proved to be NADPH-dependent. It exhibits good bioactivity and stability at $37{ }^{\circ} \mathrm{C}, \mathrm{pH} 6.0$. AKR3-2-9 is catalytically active on 11 pairs of substrates such as 3-methylcyclohexanone and methyl pyruvate, among which it showed the highest catalytic activity for acetylacetone. In addition, AKR3-2-9 was able to be resistant to five common organic solvents such as methanol and ethanol, it retained high catalytic activity even in a reaction system containing $10 \% \mathrm{v} / \mathrm{v}$ organic solvent for $6 \mathrm{~h}$, which indicates its broad substrate spectrum and exceptional organic solvent tolerance. Furthermore, its three-dimensional structure was constructed and catalytic-site-analysis of the enzyme was conducted. Notably, it was capable of catalyzing the reaction of the key intermediates of duloxetine. The extensive substrate spectrum and predominant organic solvents resistance makes AK3-2-9 a promising enzyme which can be potentially applied in medicine synthesis.
\end{abstract}

Keywords: aldo-keto reductase; enzyme assay; organic solvents; chiral alcohol; substrate spectrum

\section{Introduction}

Chiral alcohols are compounds with hydroxyl groups on the chiral carbon atoms. Based on this structure, other sites may have different functional groups or substituents, such as aromatic alcohols, fatty alcohols, and transoxides [1-3]. Chiral alcohols and their derivatives are important intermediates of the synthesis of chiral drugs [4], chiral pesticides and many chemical materials like liquid crystal materials, thus they play an increasingly important role in medicine and other chemical fields $[5,6]$. Traditionally, chiral alcohols can be synthesized by chemical methods which were proved to be harsh for the complicated preparation process, severe environmental pollution and low selectivity of the product enantiomer [7,8]. In contrast to chemical methods, biological methods show the advantages of mild conditions, low-environmental pollution, strong substrate specificity, high stereoselectivity and regioselectivity, and high product enantiomeric purity $[9,10]$. Biocatalytic synthesis of chiral alcohols provides an efficient strategy in the preparation of pharmaceutical intermediates [11], which is a green and sustainable synthetic route [12].

The aldo-keto reductases (AKRs) are one of the three super families that perform oxidoreduction on a wide variety of natural and foreign substrates [13]. The AKRs catalyze the reduction of different acids or ketones to form the corresponding alcohols with the participation of NAD(P)H [14]. With the strength of high chemo-, enantio-, and regioselectivity, the reduction of prochiral carbonyl 
compounds mediated by AKRs is of great potential in the preparation of single enantiomers of chiral alcohols. However, challenges still remain in the cloning, purification, characterization and application in the asymmetric synthesis of AKRs. Yuan-Hui Ma et al. cloned an AKR gene from Thermotoga maritimeit (Tm1743) with broad substrate specificity towards various keto esters, ketones and aldehydes [15]. Yun Hee Choi et al. cloned an AKR gene, YOL151W, from Saccha-romyces cerevisiae to realize the asymmetric synthesis of (S)-3-chloro-1-phenyl-1-propanol [16]. Similarly, all of these AKRs, alkyl 4-halo-3-oxobutyrate reductase from Penicillium citrinum IFO4631 [17], the carbonyl-reducing enzymes from C. albicans [18], an AKR gene (klakr) from Kluyveromyces lactis XP1461 [19], can also be used for the synthesis of chiral alcohols. Nevertheless, compared to carbonyl reductase and alcohol dehydrogenase, the synthesis of AKRs for chiral alcohols is still rare and worthy of further study $[20,21]$.

In this study, an aldo-keto reductase (AKR3-2-9) was cloned from Bacillus sp., and its catalytic performance was analyzed. Meanwhile, the three-dimensional structure was also constructed and catalytic-site-analysis of the enzyme was executed. The results showed that AKR3-2-9 has a broad substrate spectrum and excellent organic solvent tolerance, making it a promising biocatalyst for the synthesis of chiral alcohols.

\section{Results}

\subsection{Cloning and Sequencing Analysis of AKR3-2-9}

AKR3-2-9 encodes a putative polypeptide of 311 amino acid residues with a predicted molecular mass of $36.2 \mathrm{kDa}$. The deduced amino acid sequence of the AKR3-2-9 gene was submitted to the NCBI database (http://www.ncbi.nlm.nih.gov/) and then blasted. (The GenBank accession number MK503097) The results of the multiple sequence alignment of NCBI protein explosion are shown in Figure 1. The sequence of AKR3-2-9 displayed similarity to the identical proteins from others Bacillus. The identities of AKR3-2-9 with other proteins were shown as follows: $99 \%$ with AKR from Bacillus aryabhattai (NO.: WP_098627560.1), 98\% with AKR family oxidoreductase from Bacillus megaterium (NO.: WP_116076470.1), 82\% with AKR from Bacillus sonorensis (NO.: WP_006637001.1), 77\% with AKR family oxidoreductase from Bacillus endophyticus (NO.: WP_113749864.1), 73\% with AKR from Bacillus galactosidilyticus (NO.: WP_064468779.1), 68\% with AKR from Brevibacillus sp. OK042 (NO.:WP_092270417.1), 68\% with AKR from Paenibacillus pectinilyticus (NO.: WP_065854942.1), 62\% with AKR from Thermoanaerobacter thermocopriae (NO.: KUJ89763.1), and 26\% with MULTISPECIES: AKR from Microcystis (NO.:WP_008205609.1). 

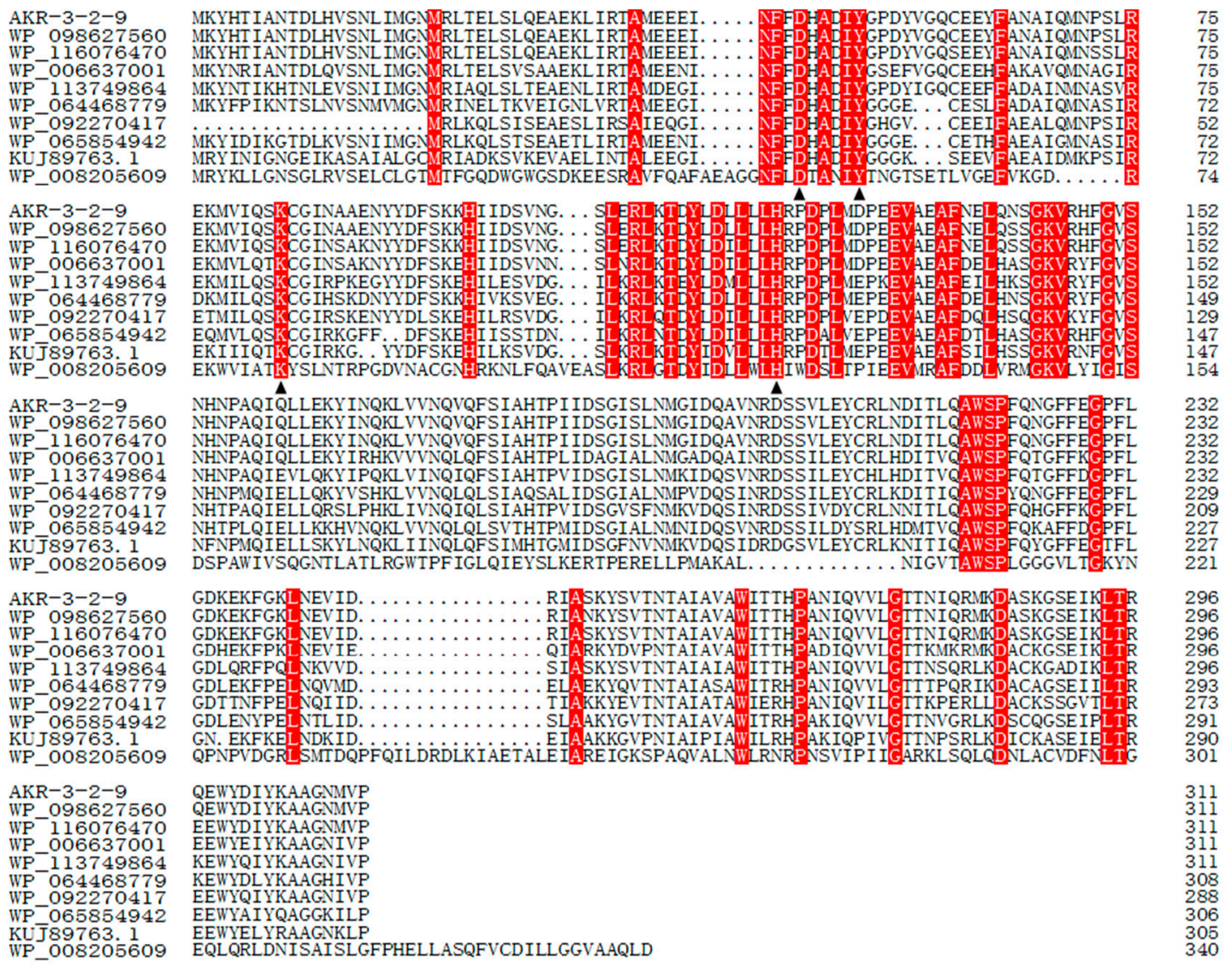

Figure 1. Alignment of multiple deduced amino acid sequences of AKR3-2-9 and others AKRs. Conserved sites are all marked in red and catalytically active tetrads $\left(\mathrm{DX}_{4} \mathrm{YX}_{31} \mathrm{KX}_{38} \mathrm{H}\right)$ are marked with black triangles.

\subsection{Expression and the Purification of AKR3-2-9}

SDS-PAGE analysis indicated that the AKR3-2-9 was successfully expressed, most in the soluble form (Figure 2). Recombinant AKR3-2-9 was further purified using the Ni-IDA column due to the presence of the His-tagged fusion protein. The further purified AKR3-2-9 exhibited a single band with a molecular weight of approximately $36.2 \mathrm{kDa}$, which is consistent with the predicted results.

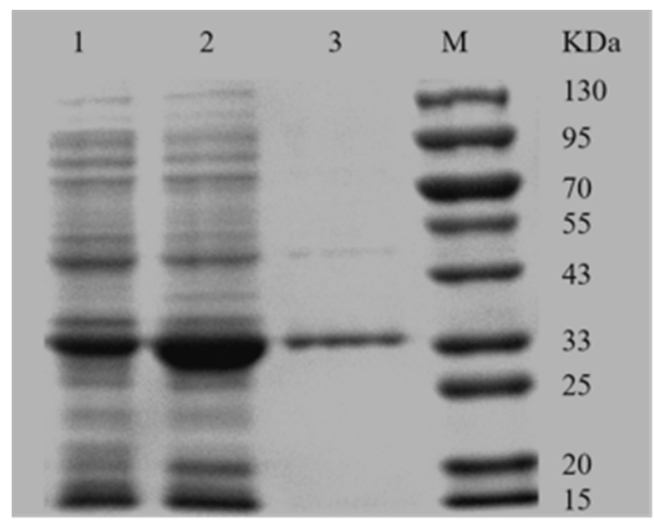

Figure 2. SDS-PAGE analysis of expression products. Lane 1, not induced with IPTG; lane 2, crude enzyme solution after IPTG induction; lane 3, purified AKR3-2-9; lane M: marker. 


\subsection{Substrate Specificity}

To investigate the substrate specificity of AKR3-2-9, we studied the catalytic efficiency of AKR3-2-9 for various ketones and keto acids. AKR3-2-9 showed varying degree of catalytic activity to different substrates (Figure 3), indicating that AKR3-2-9 has a broad substrate spectrum. Among the substrates, 3-methylcyclohexanone, 2-octanone and phenyl methyl ketone had less than $40 \%$ enzyme activity and 2 -octanone had the lowest activity. Most of the relative activity was higher than $60 \%$. The activity of acetylacetone was the highest.

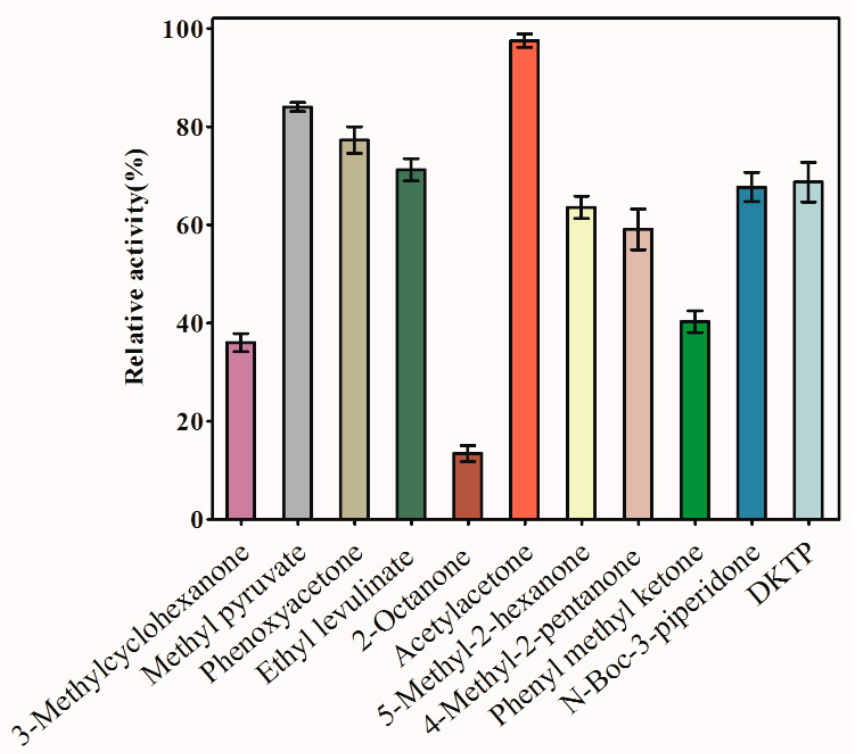

Figure 3. Substrate specificity of the enzyme. Substrate specificity of the carbonyl substrate to be tested for the enzyme, including 3-methylcyclohexanone, methyl pyruvate, phenoxyacetone, ethyl levulinate, 2-octanone, acetylacetone, 5-methyl-2-hexanone, 4-methyl-2-pentanone, phenylmethylketone, N-Boc-3-piperidone, DKTP. The reaction mixture $(220 \mu \mathrm{L})$ contained $10 \mu \mathrm{L}$ of substrate, $170 \mu \mathrm{L}$ of PBS, $10 \mu \mathrm{L}$ of NADPH and $30 \mu \mathrm{L}$ of enzyme AKR 3-2-9. The experiment was performed in triplicate and the error bars represented the standard error of the mean. The maximum enzyme activity was defined as $100 \%$.

\subsection{Effect of Temperature and $p H$}

Normally, enzyme activity will be affected by temperature and $\mathrm{pH}$ conditions. As shown in (Figure 4A), the relative activity of AKR3-2-9 increased with the increment of temperature from 31 to $37^{\circ} \mathrm{C}$. At $37^{\circ} \mathrm{C}$, AKR3-2-9 has the greatest activity. After the temperature exceeded $37^{\circ} \mathrm{C}$, the enzyme activity of AKR3-2-9 began to decrease. It was different that the optimum temperature for AKR3-2-9 was higher than $30^{\circ} \mathrm{C}$ for AKR from a newly isolated Kluyveromyces lactis XP1461 [19]. The AKR3-2-9 was incubated in an environment of $30^{\circ} \mathrm{C}$ to $80^{\circ} \mathrm{C}$ to study the thermal stability of AKR 3-2-9. As shown in (Figure 4B), AKR3-2-9 retained 55\% of the enzyme activity, showing the good thermal stability at $80{ }^{\circ} \mathrm{C}$ compared to AKR from Candida albicans XP1463 which lost $80 \%$ of its enzyme activity at $50{ }^{\circ} \mathrm{C}$ [22]. As shown in (Figure 4C), AKR3-2-9 has maximum activity at $\mathrm{pH}$ 6.0, it maintained more than $60 \%$ activity in sodium phosphate buffer at $\mathrm{pH}$ 6.0-8.0, demonstrating its relatively broad catalytic $\mathrm{pH}$. When the $\mathrm{pH}$ ranges from 8.0 to 9.0, the activity of AKR3-2-9 remained above $40 \%$. However, when the $\mathrm{pH}$ is lower than 5.0, its activity dropped sharply. In addition, AKR3-2-9 reduced its activity in sodium citrate and Tris- $\mathrm{HCl}$ buffers at the same $\mathrm{pH}$ compared to sodium phosphate buffer. To investigate the $\mathrm{pH}$ stability, AKR3-2-9 was incubated for $24 \mathrm{~h}$ in the buffer at $\mathrm{pH}$ ranging from 4.0 to 9.0, and the reaction temperature was fixed to $4{ }^{\circ} \mathrm{C}$. As shown in (Figure 4D), AKR3-2-9 kept more than $80 \%$ activity in slightly acidic and neutral environments. However, when the $\mathrm{pH}$ was less than 5.0 and more than 
8.0, AKR3-2-9 lost most of its activity, which may due to the instability when it was exposed to extreme acidity or alkaline conditions.
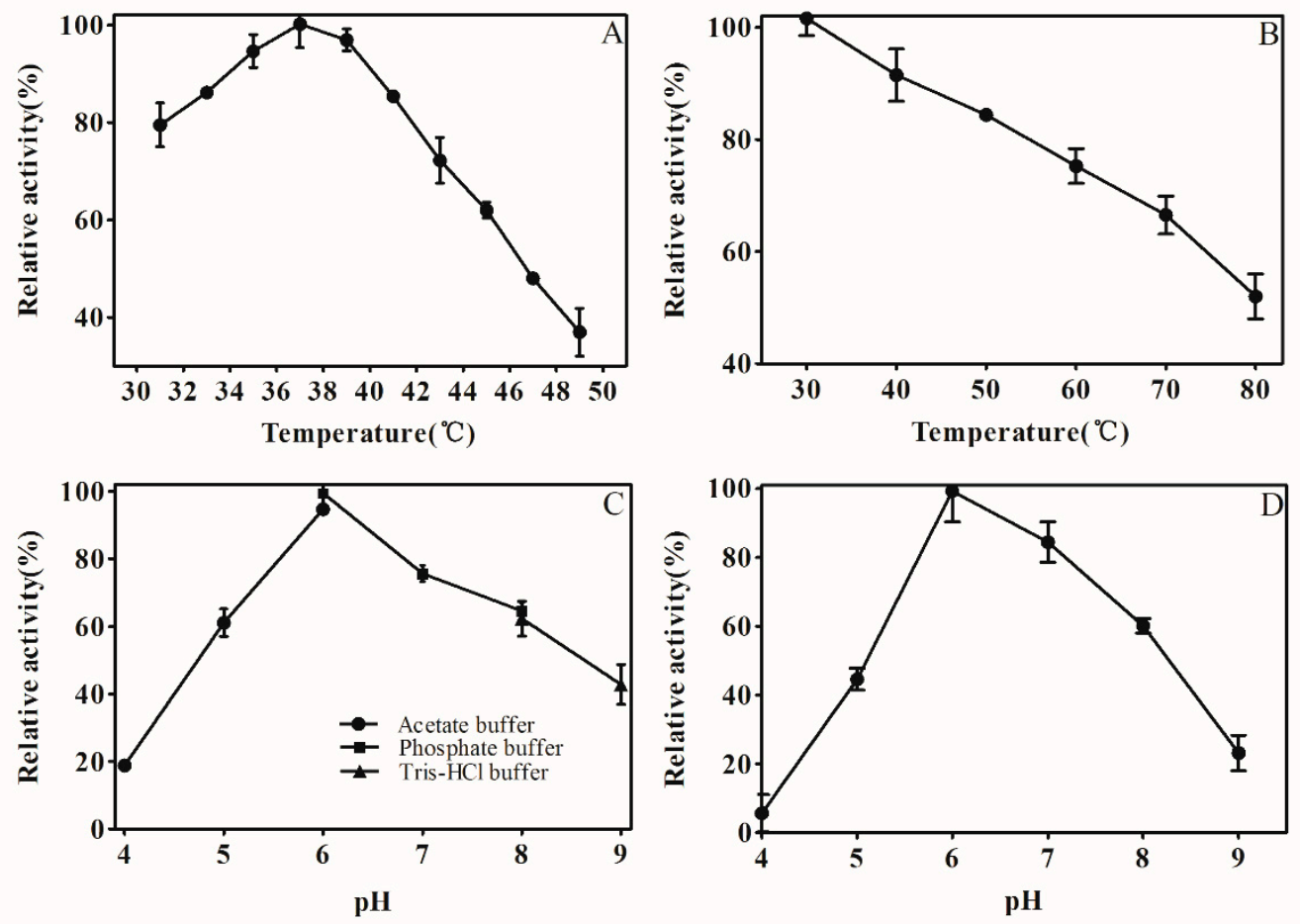

Figure 4. Effects of temperature and $\mathrm{pH}$ on AKR3-2-9 activity and stability. (A) Temperature dependence of AKR3-2-9. The enzyme activity was measured at different temperatures according to the standard assay, and the maximum enzyme activity was defined as $100 \%$. (B) The thermal inactivation curve for AKR3-2-9. AKR3-2-9 in 30 to $80^{\circ} \mathrm{C}$ for $1 \mathrm{~h}$ after incubation, according to the standard method for measuring the enzyme activity, the maximum enzyme activity was defined as $100 \%$. (C) pH dependence of AKR3-2-9. $50 \mathrm{mM}$ acetate buffer $(\bullet), 50 \mathrm{mM}$ potassium phosphate ( $\mathbf{(})$ and $50 \mathrm{mM}$ Tris- $\mathrm{HCl}(\mathbf{\Delta})$ were used. The maximum enzyme activity was defined as 100\%. (D) pH stability of AKR3-2-9. AKR3-2-9 was incubated at $4{ }^{\circ} \mathrm{C}, \mathrm{pH} 4.0-9.0$ for up to $24 \mathrm{~h}$. The residual activities were assessed under the standard assay conditions. The maximum enzyme activity was defined as $100 \%$. The experiment was performed in triplicate and the error bars represented the standard error of the mean.

\subsection{Detection of AKR3-2-9 Tolerant Organic Solvent Properties}

Five common organic solvents, methanol, ethanol, isopropanol, acetonitrile and DMSO were selected to study the tolerance of the organic solvent of AKR3-2-9. The result is shown in Figure 5. In the reaction system, five different kinds of organic solvents with different concentrations (10-30\% v/v) were added respectively, and AKR3-2-9 remained relatively high enzyme activity. This suggests that AKR3-2-9 has a strong organic solvent tolerance. Commonly, organic solvents are essential in drug synthesis, and AKR3-2-9's superior organic solvent tolerance indicates the possibilities of applications in biomedical field. 


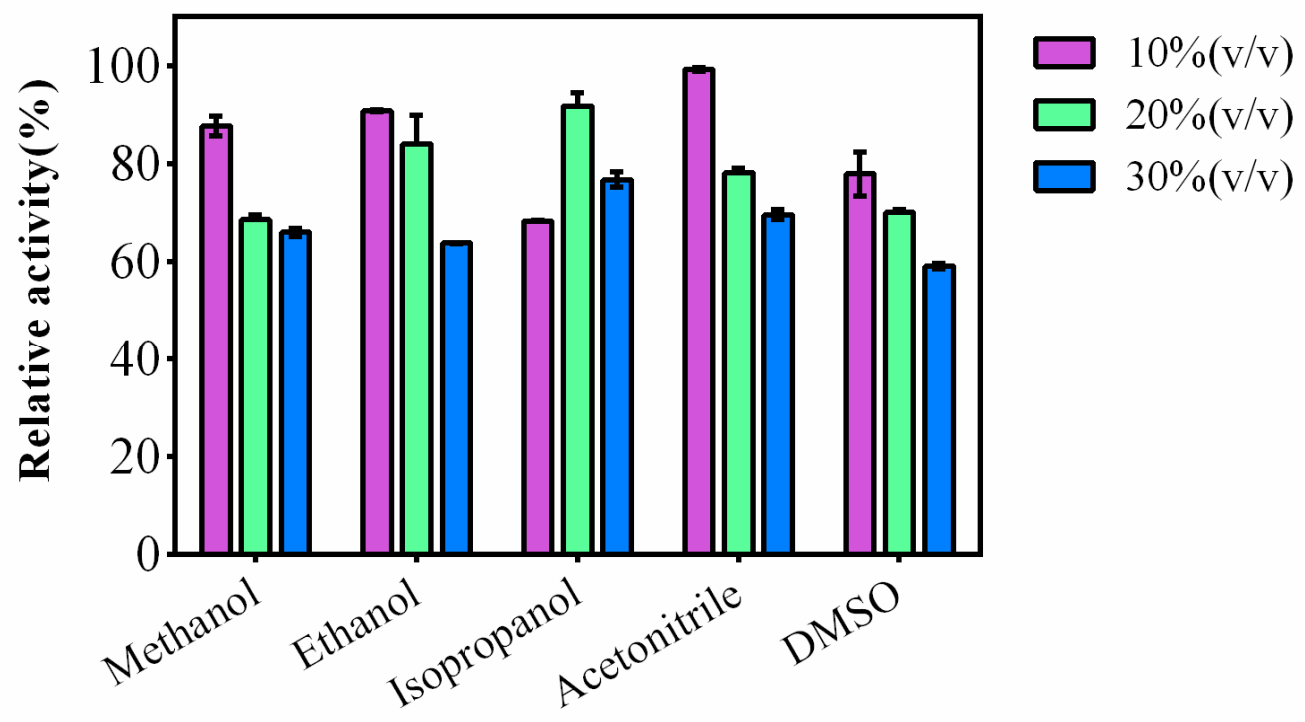

Figure 5. AKR3-2-9 is resistant to six different organic solvents, methanol, ethanol, isopropanol, acetonitrile and DMSO. Each organic solvent has a gradient of $10-30 \%(\mathrm{v} / \mathrm{v})$. The enzyme activity of AKR3-2-9 was measured using standard methods. The experiment was performed in triplicate and the error bars represented the standard error of the mean. The enzyme activity of AKR3-2-9 was measured using standard methods.

\subsection{Kinetic Analysis}

The kinetic parameters of the purified AKR3-2-9 to DKTP, acetylacetone, phenoxyacetone and methyl pyruvate substrates are shown in Table 1 . The results showed that from the $K_{m}$ value, AKR3-2-9 had a minimum $K_{\mathrm{m}}$ value of $2.81 \mathrm{mM}$ for DKTP. From the perspective of $k_{\text {cat }} / K_{\mathrm{m}}$, AKR3-2-9 has the largest $k_{\text {cat }} / K_{\mathrm{m}}$ value of $0.667 \times 10^{3} \mathrm{~s}^{-1} \mathrm{mM}^{-1}$ for acetylacetone.

Table 1. Kinetic parameters of AKR3-2-9 on four substrates.

\begin{tabular}{cccc}
\hline Substrate & $\boldsymbol{K}_{\mathbf{m}}(\mathbf{m M})$ & $\boldsymbol{k}_{\text {cat }}\left(\mathbf{s}^{\mathbf{- 1}}\right)$ & $\boldsymbol{k}_{\text {cat }} / \boldsymbol{K}_{\mathbf{m}}\left(\mathbf{s}^{\mathbf{- 1}} \mathbf{m M}^{-\mathbf{1}}\right)$ \\
\hline Acetylacetone & $6.29 \pm 0.36$ & $(4.195 \pm 0.08) \times 10^{3}$ & $0.667 \times 10^{3}$ \\
Methyl pyruvate & $7.431 \pm 0.47$ & $(4.24 \pm 0.09) \times 10^{3}$ & $0.571 \times 10^{3}$ \\
Phenoxyacetone & $9.844 \pm 0.82$ & $(3.648 \pm 0.12) \times 10^{3}$ & $0.371 \times 10^{3}$ \\
DKTP & $2.81 \pm 0.78$ & $(1.601 \pm 0.19) \times 10^{3}$ & $0.569 \times 10^{3}$ \\
\hline
\end{tabular}

\subsection{The Activity towards DKTP}

To further determine the activity towards DKTP, nuclear magnetic resonance analysis was used to determine if (S)- $N$, N-dimethyl-3-hydroxy-3-(2-thienyl)-1-propanamine (S-DHTP) was present in the culture. When DKTP was reduced to $S$-DHTP, a significant chemical shift occurs in ${ }^{13} \mathrm{C}$ on the carbonyl group. The Figure 6A shows the reaction of AKR3-2-9 to catalyze the formation of S-DHTP by the substrate DKTP. The Figure $6 \mathrm{~B}$ is a ${ }^{13} \mathrm{C}$ NMR chart of the substrate DKTP and the product $S$-DHTP. The results showed that the chemical shift of ${ }^{13} \mathrm{C}(\mathrm{e})$ on the substrate DKTP carbonyl was $192 \mathrm{ppm}$, while the chemical shift of ${ }^{13} \mathrm{C}(5)$ on the product $S$-DHTP was $58 \mathrm{ppm}$. Obviously, under the catalysis of AKR3-2-9, DKTP undergoes a reduction reaction, resulting in S-DHTP. Therefore, we can confirm that AKR3-2-9 has the potential to catalyze the formation of $S$-DHTP by the substrate DKTP. Since NMR can only be qualitatively analyzed, in subsequent studies we will also analyze the reaction by high performance liquid chromatography (HPLC). 

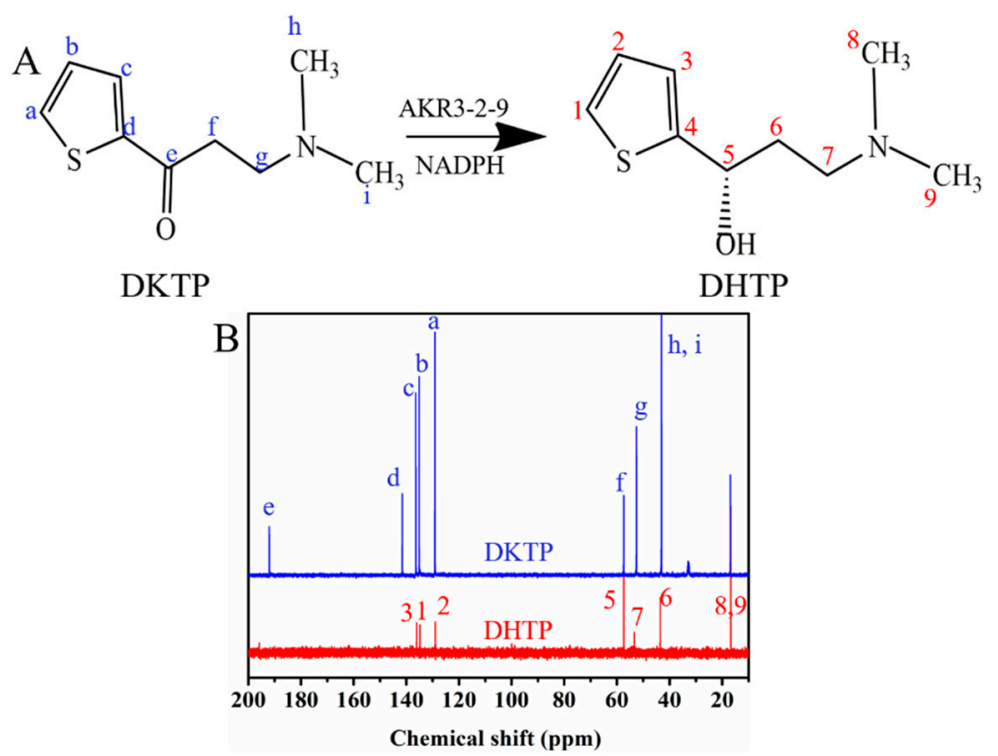

Figure 6. The activity towards DKTP. (A) The reaction of AKR3-2-9 catalyzing the substrate DKTP to generate $S$-DHTP. (B) The ${ }^{13} \mathrm{C}$ NMR chart of the substrate DKTP and the product DHTP.

\subsection{Molecular Modeling}

Homology modeling of AKR3-2-9 was constructed by using SWISS-MODEL, which showed the unique three-dimensional protein structure (Figure 7A). The three subunits are tightly clasped together in a geometrically symmetrical shape, indicating that AKR3-2-9 is very conservative. In addition, we also evaluated the structure of AKR3-2-9, as shown in (Figure 7B). The results show that the model of AKR3-29 is reliable. In addition, the crystal structure of AKR3-2-9 and AKR (Ydhf) from E. coli has a similarity of $42.76 \%$ (SMTL ID: 1 og6.1, an AKR derived from E. coli complexed with NADPH). The sequence alignment of AKR3-2-9 is shown in Figure S1.
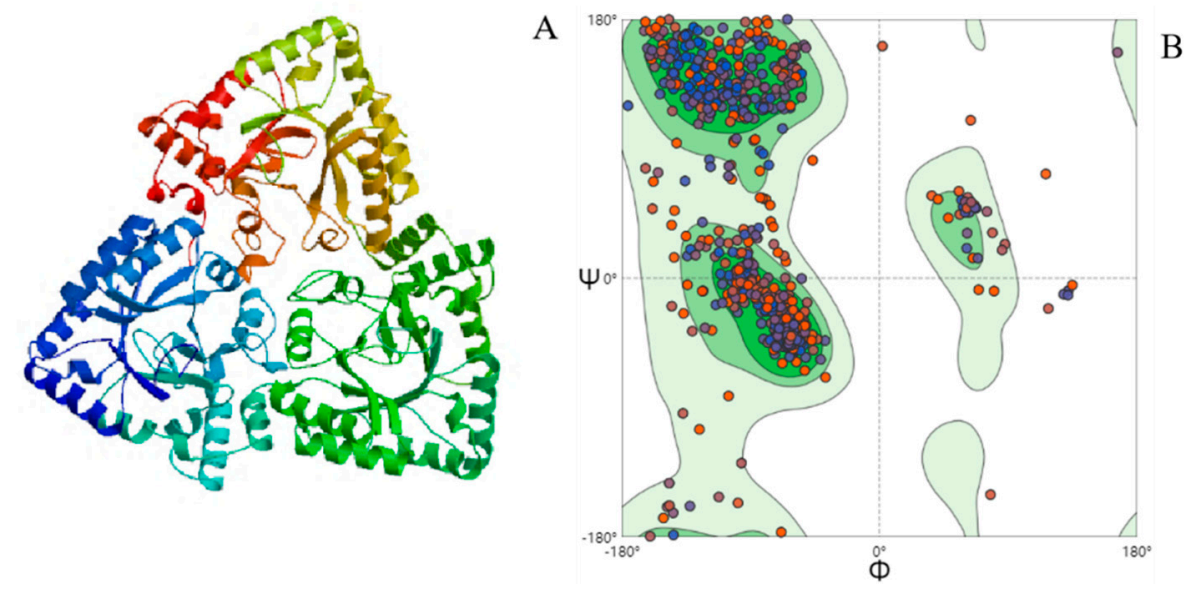

Figure 7. (A) The 3D model of AKR3-2-9. (B) Raman diagram for AKR3-2-9 model evaluation.

\section{Discussion}

According to the sequencing analysis of AKR3-2-9, these amino acid sequences share the same conserved sites, particularly the conserved sites of Asp47, Tyr51, Lys83 and His122, which constitute catalytic tetranes of AKR [23]. So far, the role of these four amino acids in catalytic and coenzyme binding motifs remains unclear, and has not been studied very thoroughly-especially for Asp, whose function is still unclear. Several studies on the clarification of AKR crystal structure and site-directed mutagenesis have shown that Lys residues function in electrostatic interaction and contribute to 
electrostatic stability $[24,25]$. The Tyr residue binds to the substrate and participates in the carbonyl reduction reaction [26] while His residue is critical to the proton relay [27,28].

In addition, based on the substrate specificity results of AKR3-2-9, it is worth mentioning that AKR3-2-9 has more than 70\% relative enzyme activity on (DKTP), This indicates that it is capable of the enantioselective reduction of DKTP to S-DHTP, a key intermediate in the synthesis of the drug duloxetine $[29,30]$. This result illustrates that AKR3-2-9 enables the production of duloxetine with high application values. Previously, Chen Liang et al. reported that AKRs by gene mining have a relatively broad substrate spectrum with only five substrates [18].

Most medicine is synthesized in organic solvent, and thus the organic solvent tolerance of the enzyme is very important. AKR3-2-9 exhibited excellent organic solvent tolerance compared to the AKRs from Kluyveromyces lactis which can only withstand 5\% v/v organic solvent [19]. Interestingly, in the reaction system containing isopropanol, the enzyme activity of AKR3-2-9 maintained the highest activity, at $20 \%$ organic solvent concentration. We assume that an appropriate amount of isopropanol tends to alter the spatial transformation of AKR3-2-9, thereby enhancing enzyme activity. However, the exact reaction mechanism is unclear. In subsequent studies, we can use it to test the circular dichroism (CD) of the natural structure of proteins in organic solvents under different $\mathrm{pH}$ and temperature conditions, so that we can better study the reaction of AKR3-3-9 tolerating organic solvents mechanism.

The $K_{\mathrm{m}}$ values to represents the affinity of the enzyme for the substrate, while $k_{\text {cat }} / K_{\mathrm{m}}$ represents the catalytic efficiency of the enzyme [31]. In contrast, AKR3-2-9 has a stronger substrate affinity for DKTP and a stronger catalytic efficiency for acetylacetone.

The structural novelty of the enzyme is of great importance. To demonstrate the novelty of the AKR3-2-9 structure, the structure of other AKRs were searched for in the protein data bank (PDB). In the PDB, a total of 285 structures were found, of which 43 were from bacteria. The structure of these 43 AKRs were summarized (See Figure S2). The results show that AKR3-2-9 is completely different from the other 42 structures, and the similarity with one of the structures (PDB ID: 1UR3) is only $42.76 \%$. This suggests that the structure of AKR3-2-9 is very novel. The three subunits of AKR3-2-9 are tightly entangled to form a symmetrical structure. This structure is closely linked. Because of this, in view of the strong organic solvent tolerance of AKR3-2-9, it is very related to the structure of AKR3-2-9. It is very likely that the organic solvent cannot easily destroy the spatial structure of AKR3-2-9.

\section{Materials and Methods}

\subsection{Strains, Vectors, Chemicals}

Escherichia coli DH5 $\alpha$ was used for cloning, and E. coli BL21 (DE3) was used for heterologous expression. They were cultivated in Luria-Bertani (LB) medium. Plasmid pET-28a was utilized for heterologous expression studies. All enzymes used in this study were from TaKaRa Co., Ltd. (Dalian, China). The Plasmid Mini Kit I (200) and Gel Extraction Kit (200) were purchased from OMEGA Co. (USA). NADPH was purchased from Sigma-Aldrich Co. (Shanghai, China). All the other chemicals were chromatographically pure or analytically graded and used without further purification, and they were obtained from Aladdin (Germany).

\subsection{Homologous Protein-Searching Analysis and Homology Modeling}

The BLAST tool at NCBI (https://blast.ncbi.nlm.nih.gov/Blast.cgi) was used to discover sequences similar to AKR3-2-9. Nine other sources of AKRs were selected from all blast results and subjected to multiple sequence alignment analysis used DNAMEN. Homology modeling was constructed by SWISS MODEL (http://swissmodel.expasy.org/) with the sequence of AKR3-2-9 [32].

\subsection{Cloning, Expression and Purification of AKR3-2-9}

The primer of AHR3-2-9 gene was synthesized by Bioengineering Biotechnology (Shanghai) Co., Ltd., and the target gene was amplified by bacterial PCR. The DNA fragment was then 
sub cloned into the original vector of pET-28a to construct a recombinant expression vector pET-28a-akr3-2-9, which was finally transformed into E. coli BL21 (DE3) cells. The E. coli BL21 (DE3) was cultured in $200 \mathrm{~mL}$ of LB medium ( $\mathrm{pH}$ 6.5) containing $100 \mu \mathrm{g} / \mathrm{mL}$ of ampicillin at $37^{\circ} \mathrm{C}$, $200 \mathrm{rpm}$. The temperature was changed to $18^{\circ} \mathrm{C}$ when the optical density at $600 \mathrm{~nm}$ (OD 600) reached $0.6-0.8$, then isopropyl- $\beta$-D-thiogalactoside(IPTG) was added with a final concentration of $0.1 \mathrm{mM}$, and the cultivation was continued for another $14 \mathrm{~h}$. The cells were then harvested by recombinant centrifugation ( $5000 \mathrm{rpm}, 3 \mathrm{~min}$ ) and washed three times with PBS at $4{ }^{\circ} \mathrm{C}$ and stored at $4{ }^{\circ} \mathrm{C}$ for further usage. The cell pellet was suspended in PBS and disrupted by sonication. Subsequently, the disrupted cell debris was centrifuged for $20 \mathrm{~min}$ to remove the precipitate at $12,000 \mathrm{rpm}, 4^{\circ} \mathrm{C}$. Afterwards, his-tagged enzyme was purified by an AKTA Prime system equipped with a 10-mL Ni-IDA column (GE Healthcare, USA). Finally, the results of expression and purification of the enzyme were characterized by $12 \%$ SDS-PAGE and the pure protein concentration was determined by Bradford Protein Assay Kit.

\subsection{Enzyme Activity Assays and Kinetic Parameter Studies}

The rates of reduction were assayed at $37^{\circ} \mathrm{C}$ by measuring the change of NADPH absorbance at $340 \mathrm{~nm}\left(\varepsilon=6.22 \mathrm{mM}^{-1} \mathrm{~cm}^{-1}\right)$. The reaction mixture $(220 \mu \mathrm{L})$ contained $10 \mu \mathrm{L}$ acetylacetone, $170 \mu \mathrm{L}$ PBS, $10 \mu \mathrm{L}$ NADPH, and $30 \mu \mathrm{L}$ enzyme AKR 3-2-9. One unit of AKR 3-2-9 enzyme activity was defined as the amount of enzyme that catalyzed the oxidation of $1 \mu \mathrm{mol}$ NADPH per minute. The protein concentration was estimated using the Bradford method. The $k_{\text {cat }}$ and apparent Michaelis-Menten constant $\left(K_{\mathrm{m}}\right)$ of the enzyme were calculated by the Lineweaver-Burk double-reciprocal plot.

\subsection{Characterization of the AKR 3-2-9}

\subsubsection{Substrate Specificity of AKR3-2-9}

In order to study the substrate spectrum, the reduction of aldehydes, ketones and ketoesters catalyzed by AKR3-2-9 was investigated under standard assay conditions. The reaction mixture $(220 \mu \mathrm{L})$ contained $10 \mu \mathrm{L}$ substrate, $170 \mu \mathrm{L}$ PBS, $10 \mu \mathrm{L}$ NADPH, and $30 \mu \mathrm{L}$ AKR 3-2-9. The residual maximum activity was set as $100 \%$. Eleven substrates, 3-Methylcyclohexanone, methyl pyruvate, phenoxyacetone, ethyl levulinate, 2-octanone, acetylacetone, 5-methyl-2-hexanone, 4-methyl-2-pentanone, phenyl methyl ketone, $N$-boc-3-piperidone and $N, N$-dimethyl-3-keto-3-(2-thienyl)-1-propanamine (DKTP) were utilized.

\subsubsection{Effect of Temperature and $\mathrm{pH}$}

By preincubation the reaction system (without NADPH) at the specific temperature for $5 \mathrm{~min}$, the enzyme activity was detected at the temperature ranging from 30 to $50{ }^{\circ} \mathrm{C}$ to study the optimum temperature. The thermal stability of the enzyme was determined by pre-incubation the enzyme at temperatures of 30 to $80^{\circ} \mathrm{C}$ for $1 \mathrm{~h}$ and then the residual enzyme activity was detected using the method described above.

To study the $\mathrm{pH}$ effect on the enzyme, the activity of purified AKR3-2-9 activity was assayed in $50 \mathrm{mM}$ buffers systems with $\mathrm{pH}$ 4.0-6.0, $\mathrm{pH}$ 6.0-8.0 and $\mathrm{pH}$ 8.0-9.0, which were made of acetate buffer, phosphate buffer and Tris- $\mathrm{HCl}$ buffer, respectively. The $\mathrm{pH}$ stability of the enzymes was measured by pre-incubating them in different $\mathrm{pH}$ value of $\mathrm{pH} 4.0-9.0$ at $4{ }^{\circ} \mathrm{C}$ for $24 \mathrm{~h}$. Then, the residual activity of the incubated samples was measured according to the standard method. The substrate of the reaction system was acetylacetone.

\subsubsection{Organic Solvent Tolerance of AKR3-2-9}

The effect of organic solvents on AKR3-2-9 was exploited by adding different organic solvents $(10 \%, 20 \%, 30 \%) \mathrm{v} / \mathrm{v}$ to the reaction system. In this experiment, methanol, ethanol, isopropanol, acetonitrile and dimethyl sulfoxide (DMSO) were used. The residual activity of the incubated samples 
was then calculated according to standard methods. The original activity was designated as $100 \%$. The substrate of the reaction system was DKTP.

\subsection{The Activity towards DKTP}

A quantity of $0.05 \mathrm{~g}$ of DKTP was dissolved in the AKR3-2-9 enzyme solution, and a sufficient amount of NADPH was added. Then, it was then placed in a shaker for $24 \mathrm{~h}$ at $37^{\circ} \mathrm{C}, 200 \mathrm{rpm}$. The reaction product was analyzed by nuclear magnetic resonance (NMR).

\subsection{The GenBank Accession Number of the AKR3-2-9}

The GenBank accession number of the sequence reported in this paper is MK503097.

\section{Conclusions}

A novel ketone reductase (AKR3-2-9) was obtained, which has good thermolability and $\mathrm{pH}$ stability, broad substrate spectrum, predominant organic solvent tolerance and the ability to catalyze the synthesis of key intermediates of duloxetine, which makes it a promising enzyme with potential applications in medical field. Moreover, the homology modeling and sequence analysis of AKR3-2-9 were conducted to further clarify the mechanism of organic solvent tolerance. Due to the advantages of biosynthesis, an increasing number of enzymes for adaption to the drug synthesis conditions are required to be excavated and even designed, to hence promote the development of medicine production. In this work, the obtained AKR3-2-9 possessed superior characteristics; its application and mechanism of organic solvent tolerance require further investigation in the future.

Supplementary Materials: The following are available online at http://www.mdpi.com/2073-4344/10/10/1121/s1, Figure S1: Alignment of the sequence of AKR3-2-9 with the sequence of 1og6.1, Figure S2: Summary of the structure of other aldo-keto reductases in the PDB.

Author Contributions: Data curation, R.P., W.W. and L.T.; writing-original draft, R.P.; writing-review and editing, R.P., Y.Z., W.J. and S.-F.Z. All authors have read and agreed to the published version of the manuscript.

Funding: The work was supported by the National Natural Science Foundation of China (No.21808073), the Fundamental Research Funds for the Central Universities (No. ZQN-814), the high level personnel activation fee of Huaqiao University (No. 600005-Z17Y0072), and Quanzhou City Science \& Technology Program of China (No.2018C008) and Postgraduates' Innovative Fund in Scientific Research of Huaqiao University.

Acknowledgments: The work was supported by Postgraduates' Innovative Fund in Scientific Research of Huaqiao University.

Conflicts of Interest: The authors state that they have no competing interests.

\section{References}

1. Khan, I.A.; Saxena, A.K. Metal-Free, mild, nonepimerizing, chemo-and enantio- or diastereoselective $\mathrm{N}$-Alkylation of amines by alcohols via oxidation/imine-iminium formation/reductive amination: A pragmatic synthesis of octahydropyrazinopyridoindoles and higher ring analogues. Cheminform 2014, 45, 11656-11669. [CrossRef]

2. Zhou, X.; Zheng, D.; Cui, B.; Han, W.; Chen, Y. Novozyme 435 lipase mediated enantioselective kinetic resolution: A facile method for the synthesis of chiral tetrahydroquinolin-4-ol and tetrahydro-1H-benzo[b]azepin-5-ol derivatives. Tetrahedron 2015, 71, 4738-4744. [CrossRef]

3. Fish, R.H. 1,4-NADH biomimetic co-factors with horse liver alcohol dehydrogenase (HLADH), utilizing $\left[\mathrm{Cp}^{*} \mathrm{Rh}(\mathrm{bpy}) \mathrm{H}\right](\mathrm{OTf})$ for co-factor regeneration, do in fact, produce chiral alcohols from reactions with achiral ketones. Catalysts 2019, 9, 562. [CrossRef]

4. Tekedar, H.C.; Sanli-Mohamed, G. Molecular cloning, over expression and characterization of thermoalkalophilic esterases isolated from Geobacillus sp. Extremophiles 2011, 15, 203-211. [CrossRef]

5. Woodley, J.M. New opportunities for biocatalysis: Making pharmaceutical processes greener. Trends Biotechnol. 2008, 26, 321-327. [CrossRef] 
6. Kataoka, M.; Kita, K.; Wada, M.; Yasohara, Y.; Hasegawa, J.; Shimizu, S. Novel bioreduction system for the production of chiral alcohols. Appl. Microbiol. Biotechnol. 2003, 62, 437. [CrossRef]

7. Deechongkit, S.; You, S.L.; Kelly, J.W. Synthesis of all nineteen appropriately protected chiral alpha-hydroxy acid equivalents of the alpha-amino acids for boc solid-phase depsi-peptide synthesis. Org. Lett. 2004, 6, 497-500. [CrossRef]

8. Li, B.; Li, Y.; Bai, D.; Zhang, X.; Yang, H.; Wang, J.; Liu, G.; Yue, J.; Ling, Y.; Zhou, D. Whole-cell biotransformation systems for reduction of prochiral carbonyl compounds to chiral alcohol in Escherichia coli. Sci. Rep. 2014, 4, 6750. [CrossRef]

9. Goldberg, K.; Schroer, K.; Lutz, S.A. Biocatalytic ketone reduction-a powerful tool for the production of chiral alcohols-part II: Whole-cell reductions. Appl. Microbiol. Biotechnol. 2007, 76, 249-255. [CrossRef]

10. Gröger, H.; Chamouleau, F.; Orologas, N.; Rollmann, C.; Drauz, K.; Hummel, W.; Weckbecker, A.; May, O. Enantioselective reduction of ketones with "designer cells" at high substrate concentrations: Highly efficient access to functionalized optically active alcohols. Angew. Chem. Int. Ed. Engl. 2010, 45, 5677-5681.

11. Junhua, T.; Jian-He, X. Biocatalysis in development of green pharmaceutical processes. Curr. Opin. Chem. Biol. 2009, 13, 43-50.

12. Zhang, Y.; Ji, F.L.; Wang, J.Y.; Pu, Z.J.; Jiang, B.; Bao, Y.M. Purification and characterization of a novel organic solvent-tolerant and cold-adapted lipase from Psychrobacter sp. ZY124. Extremophiles 2018, 22, 287-300. [CrossRef]

13. Penning, T.M. The aldo-keto reductases (AKRs): Overview. Chem.-Biol. Interact. 2015, 234, $236-246$. [CrossRef] [PubMed]

14. Hyndman, D.; Bauman, D.R.; Heredia, V.V.; Penning, T.M. The aldo-keto reductase superfamily homepage. Chem.-Biol. Interact. 2003, 143, 621-631. [CrossRef]

15. Lv, D.-Q.; Zhou, S.; Lai, D.-Y.; Chen, Z.-M.; Ma, Y.-H. Characterization of an aldo-keto reductase from Thermotoga maritima with high thermostability and a broad substrate spectrum. Biotechnol. Lett. 2013, 35, 757-762.

16. Hee, C.Y.; Hye Jeong, C.; Dooil, K.; Ki-Nam, U.; Hyung-Kwoun, K. Asymmetric synthesis of (S)-3-chloro-1-phenyl-1-propanol using Saccharomyces cerevisiae reductase with high enantioselectivity. Appl. Microbiol. Biotechnol. 2010, 87, 185-193.

17. Asako, H.; Wakita, R.K.; Shimizu, M.; Sakai, J.; Itoh, N. Purification and cDNA cloning of NADPH-dependent aldoketoreductase, involved in asymmetric reduction of methyl 4-bromo-3-oxobutyrate, from Penicillium citrinum IFO4631. Appl. Environ. Microbiol. 2005, 71, 1101-1104. [CrossRef]

18. Chen, L.; Yao, N.; Mu, X.; Yan, X. Gene mining-based identification of aldo-keto reductases for highly stereoselective reduction of bulky ketones. Bioresour. Bioprocess. 2018, 5, 33.

19. Luo, X.; Wang, Y.J.; Zheng, Y.G. Cloning and characterization of a NADH-dependent aldo-keto reductase from a newly isolated Kluyveromyces lactis XP1461. Enzym. Microb. Technol. 2015, 77, 68-77. [CrossRef]

20. Cao, C.; Fukae, T.; Yamamoto, T.; Kanamaru, S.; Matsuda, T. Purification and characterization of fluorinated ketone reductase from Geotrichum candidum NBRC 5767. Biochem. Eng. J. 2013, 76, 13-16. [CrossRef]

21. Zheng, G.W.; Xu, J.H. New opportunities for biocatalysis: Driving the synthesis of chiral chemicals. Curr. Opin. Biotechnol. 2011, 22, 784-792. [CrossRef] [PubMed]

22. Wang, Q.; Tingting, Y.E.; Zhuanzhuan, M.A.; Chen, R.; Xie, T.; Yin, X. Characterization and site-directed mutation of a novel aldo-keto reductase from Lodderomyces elongisporus NRRL YB-4239 with high production rate of ethyl (R)-4-chloro-3-hydroxybutanoate. J. Ind. Microbiol. Biotechnol. 2014, 41, 1-8. [CrossRef] [PubMed]

23. Ellis, E.M. Microbial aldo-keto reductases. FEMS Microbiol. Lett. 2002, 216, 123-131. [CrossRef] [PubMed]

24. Barski, O.A.; Gabbay, K.H.; Grimshaw, C.E.; Bohren, K.M. Mechanism of human aldehyde reductase: Characterization of the active site pocket. Biochemistry 1995, 34, 11264-11275. [CrossRef] [PubMed]

25. Regina, K.; Bernd, N. Electrostatic stabilization in a pre-organized polar active site: The catalytic role of Lys-80 in Candida tenuis xylose reductase (AKR2B5) probed by site-directed mutagenesis and functional complementation studies. Biochem. J. 2005, 389, 507-515.

26. Bohren, K.M.; Grimshaw, C.E.; Lai, C.J.; Harrison, D.H.; Ringe, D.; Petsko, G.A.; Gabbay, K.H. Tyrosine-48 is the proton donor and histidine-110 directs substrate stereochemical selectivity in the reduction reaction of human aldose reductase: Enzyme kinetics and crystal structure of the $\mathrm{Y} 48 \mathrm{H}$ mutant enzyme. Biochemistry 1994, 33, 2021-2023. [CrossRef] [PubMed] 
27. Liu, X.; Wang, C.; Zhang, L.; Yao, Z.; Cui, D.; Wu, L.; Lin, J.; Yuan, Y.R.; Wei, D. Structural and mutational studies on an aldo-keto reductase AKR5C3 from Gluconobacter oxydans. Protein Sci. A Publ. Protein Soc. 2015, 23, 1540-1549. [CrossRef]

28. Schlegel, B.P.; Jez, J.M.; Penning, T.M. Mutagenesis of 3 alpha-hydroxysteroid dehydrogenase reveals a "push-pull" mechanism for proton transfer in aldo-keto reductases. Biochemistry 1998, 37, 3538-3548. [CrossRef]

29. Knadler, M.P.; Lobo, E.; Chappell, J.; Bergstrom, R. Duloxetine. Clin. Pharmacokinet. 2011, 50, $281-294$. [CrossRef]

30. Soni, P.; Banerjee, U.C. Biotransformations for the production of the chiral drug (S)-Duloxetine catalyzed by a novel isolate of Candida tropicalis. Appl. Microbiol. Biotechnol. 2005, 67, 771-777. [CrossRef]

31. Eisenthal, R.; Danson, M.J.; Hough, D.W. Catalytic efficiency and $k_{\text {cat }} / K_{\mathrm{m}}$ : A useful comparator? Trends Biotechnol. 2007, 25, 247-249. [CrossRef] [PubMed]

32. Biasini, M.; Bienert, S.; Waterhouse, A.; Arnold, K.; Studer, G.; Schmidt, T.; Kiefer, F.; Cassarino, T.G.; Bertoni, M.; Bordoli, L. SWISS-MODEL: Modelling protein tertiary and quaternary structure using evolutionary information. Nucleic Acids Res. 2014, 42, 252-258. [CrossRef] [PubMed]

(C) 2020 by the authors. Licensee MDPI, Basel, Switzerland. This article is an open access article distributed under the terms and conditions of the Creative Commons Attribution (CC BY) license (http://creativecommons.org/licenses/by/4.0/). 